\title{
PRESUPUESTOS DEONTOLÓGICOS DEL JUZGADOR PARA UNA DESMITIFICACIÓN DE LA JUSTICIA ${ }^{1}$
}

\author{
Isidro de los Santos Olivo
}

Universidad Autónoma de San Luis Potosí

DOI:10.14718/CulturaLatinoam.2017.26.2.12

Podemos afirmar sin titubeos que todo Estado que se estime de constituirse en una democracia constitucional debe cuidar, sustantivamente, el perfil del capital humano que lo encarna en los tribunales constitucionales $\mathrm{y} / \mathrm{o}$ sus poderes judiciales ordinarios. No nos cabe duda de que, a partir de la confección del Estado constitucional, se ha desarrollado toda una proliferación normativa-institucional y, del mismo modo, un conjunto de estudios teóricos sobre la teleología de

1. La presente colaboración nació de la invitación de la magistrada Juana María Meza López (en calidad de delegada en el Estado de San Luis Potosí, del Instituto de Investigaciones Jurisprudenciales y de Promoción y Difusión de la Ética Judicial de la Suprema Corte de Justicia de la Nación) a participar en un diplomado de Ética Judicial celebrado durante el segundo semestre del 2014 en la Casa de la Cultura Jurídica de la SCJN, y dirigido, inicialmente, a los servidores públicos integrantes de los poderes judiciales federal y estatal del Estado de San Luis Potosí, México, y extensivamente, al foro jurídico potosino. Allí esbozamos algunas ideas sobre la importancia capital de la condición moral que deben poseer todos los jueces en los Estados constitucionales. Destacamos la oportuna participación de la magistrada Meza, como funcionaria judicial en activo, por su preocupación por la necesidad de materializar y de exigir, como prenda insustituible para el ejercicio jurisdiccional de los jueces, su posición ética y su formación valorativa. Posteriormente, esta ponencia fue revisada, reelaborada y ampliada para presentarla como ejercicio científico en la mesa de trabajo número 4 «El Poder Judicial y la Jurisdicción Constitucional» en el XII Congreso Iberoamericano de Derecho Constitucional, celebrado en la Universidad Externado, en Bogotá, en septiembre de 2015. La metodología de la propuesta apunta a ciertas intenciones y objetivos, con la finalidad de insistir en el cuidado normativo que regule el perfil ético de los encargados de impartir justicia.

Referencia: De los Santos, I. (2017). Presupuestos deontológicos del juzgador para una desmitificación de la justicia. Cultura Latinoamericana. Revista de Estudios Interculturales. 26(2), pp. 259-272. DOI: 10.14718/CulturaLatinoam.2017.26.2.12 
los jueces y su función en las sociedades políticas. Inclusive, en tiempos recientes hemos advertido una tendencia prácticamente constante y creciente en la judicialización de los problemas sociales y políticos de los Estados.

En esta línea, también podemos observar que la actividad del juzgador participa de la conocida dialéctica «politización de la justicia» y la «judicialización de la política». En definitiva, los jueces han experimentado una evolución significativa en las funciones técnicas y sustanciales en la resolución de controversias, manifestándose una actuación más protagonista, más activa para conocer nuevos problemas jurídicos no solo de los justiciables (por ejemplo, discriminación, equidad de género, desaparición forzada, arraigo, protección del medio ambiente, dignidad humana, interés superior del menor, etc.), sino también de los órganos públicos del Estado, dirimiendo los conflictos que entre ellos pudieran suscitarse, inclusive, en la protección transnacional de los derechos humanos, por mencionar solo algunos. Ante esto, se manifiesta, pues, el protagonismo judicial en la historia reciente (Gómez Sámano, 2012).

Sobre esta problemática existen trabajos teóricos serios y prolíficos, por ello no es nuestro ánimo desarrollar un estudio sobre cuál debe ser el marco constitucional y legal que regule la actuación del juzgador ni tampoco referirnos a si la actividad jurisdiccional es un ejercicio teórico-técnico, una acción racional de conocimiento o un acto de voluntad, entre otros. En todo caso, los jueces están presentes en la vida cotidiana y democrática de un país, en la vida política (en el sentido científico del término, ya que una Constitución se adjetiva de política), y nadie puede poner en duda que, en la consecución del Estado de derecho, ejercen una función determinante y trascendental.

Nuestro propósito estriba en desarrollar algunas reflexiones para enfatizar en la formación ética, en los contenidos de integridad y en los elementos axiológicos que deben poseer los servidores públicos encargados de impartir y/o administrar justicia. Este trabajo tiene el propósito de establecer ciertas premisas que permitan incidir en la necesidad de fortalecer, de cuidar o, en su caso, de desarrollar la columna ética del juzgador, como premisa inexorable para la correcta impartición de justicia. El estudio intenta crear una propuesta que pueda incidir en los aspectos normativo-institucionales en México, en su regulación constitucional y legal.

En plena era de las comunicaciones, en la que el internet y las redes sociales, en principio, son lugar común de la inmensa mayoría de los ciudadanos de los Estados nacionales, podríamos pensar que, en 
todo Estado constitucional, los destinatarios de la norma y la autoridad encargada de ejercerla deberían estar muy familiarizados con su contenido y alcance. Esto, «técnicamente», facilitaría la consolidación del llamado Estado de derecho. De esta forma, los derechos humanos y las instituciones encargadas de aplicarlos constituirían un lugar común y cotidiano en las democracias constitucionales. Lo paradójico resulta cuando contrastamos la realidad sociopolítica con los logros en materia de justicia social y de respeto a la esfera jurídica del gobernado, esto es, de la eficacia de la Constitución.

En este sentido, uno de los objetivos principales del presente estudio le apunta a establecer un planteamiento que trate de insistir en la formación ética de los togados, es decir, en las cualidades valorativas o la carga axiológico-estimativa que deben abrigar aquellos ciudadanos que, investidos de autoridad judicial y en el ejercicio de su profesión, se dediquen a la noble, delicada y altísima actividad de impartir justicia. Se trata de orientar esta propuesta para que, si fuera el caso, se advierta si la regulación en los ámbitos constitucional y legal es deficiente y, por consiguiente, es necesaria la regulación de un perfil suficiente que fortalezca el cuidado del arquetipo del juzgador -ya sea común y/o constitucional-, al que se aspira tener en un Estado de derecho. Un enjuiciador blindado éticamente está en condiciones de sortear la corrupción y evitar una contaminación en su encumbrada y trascendental función pública.

Ahora bien, no podemos entrar en el contenido de la exposición que nos ocupa si no explicamos los alcances y/o el significado del título de nuestra intervención denominada «Presupuestos deontológicos del juzgador para una desmitificación de la justicia». El término en plural presupuestos ${ }^{2}$ con el que inicia el título de la ponencia nos indica unos prenotados, algo que se da por sentado, es decir, un prius (un antes, algo que se toma como anterior o previamente; también debemos entenderlo como lo primero). Con este inicial vocablo queremos indicar que denota prioridad de tiempo, o lugar, o preferencia, esto es, que aludimos a elementos que se dan por establecidos.

La deontología se define como la ciencia o tratado de los deberes (Real Academia Española, 2014). Este término procede del griego deon (el deber) y logía, (tratado, estudio, ciencia), lo que significa, en términos generales, el entendimiento o la ciencia de lo debido. Etimológicamente equivale a «tratado o ciencia del deber».

2. La palabra presupuesto en singular tiene varias acepciones. El sentido en el que aquí la utilizamos, en plural, es la segunda definición que recoge el Diccionario de la Real Academia Española (2014), y que significa «Supuesto o suposición». 
Estos conceptos se corresponden con las virtudes cultivadas y afianzadas en el bagaje que todo juzgador debe poseer, en nuestro parecer, para estar en condiciones de impartir justicia. Tratamos de indicar que los contenidos morales y/o éticos deben prevalecer -como condición imprescindible, en la formación del enjuiciador- sobre sus capacidades y conocimientos técnico-jurídicos, como perito del derecho, en el ejercicio de la función jurisdiccional del Estado. En definitiva, la deontología se presenta en el juzgador como un requerimiento previo sin el cual toda persona que porte esta noble investidura no puede cumplir con el fin último del derecho: la justicia. Desde nuestro punto de vista, todo juez que, en su función jurisdiccional y al aplicar el derecho, pretenda la materialización de la justicia debe tener en cuenta que esta dependerá, en buena medida, de la voluntad' del sujeto encargado de impartirla. En este sentido, el gran jurista romano Ulpiano indicaba que la justicia, antes era un acto de voluntad: «Iustitia est constans et perpetua voluntas ius suum cuique tribuendi».

El telos de la deontología judicial es el servicio de la justicia y su posible concreción en la realidad social, en tanto valor supremo del ordenamiento jurídico. Ahora bien, la deontología, como lo anticipamos, se vincula estrechamente con la moral y con la ética. De esta forma, la deontología se conecta con el enjuiciador para un correcto ejercicio de la función jurisdiccional que le ha sido encomendada. Asimismo, debemos advertir que la ciencia del deber se corresponde con una manera de entender el mundo y la vida, esto es, con una filosofía del ser humano como un ser cultural.

En la última parte del título de nuestro trabajo, en lo referente a la desmitificación de la justicia, queremos indicar con el vocablo desmitificación, en tanto recurso lingüístico, que la justicia -entendida como actividad esencial del Estado que corresponde al poder judicial,

3. Voluntad proviene del latín voluntas. La Real Academia Española (2014) la define, en sus primeras cuatro acepciones, de la siguiente forma: «1. f. Facultad de decidir y ordenar la propia conducta.//2. f. Acto con que la potencia volitiva admite o rehúye una cosa, queriéndola, o aborreciéndola y repugnándola.//3. f. Libre albedrío o libre determinación. //4. f. Elección de algo sin precepto o impulso externo que a ello obligue».

La voluntad vendría a significar una cualidad o atribución de regir el accionar propio. En nuestro concepto, la voluntad la concebimos también como una especie de actitud para entender el entorno vital, con base en una concepción del mundo y de la vida, dirigida por unos valores. La voluntad de todo individuo estará moldeada por el alimento axiológico, ético, espiritual... que incorporemos a la conciencia humana. Esto permite concretar una serie de actitudes según corresponda en distintos momentos de la vida misma. El juez en el ejercicio de su potestad jurisdiccional estatal, y como conocedor o perito del derecho, estará dirigido por su voluntad, la cual se rige por su conciencia para la toma de decisiones, en su proceder mismo y en sus resoluciones. Lo que, en definitiva, supone el ejercicio de su libre albedrío y realizar toda acción que tenga que llevar a cabo para alcanzar la justicia, como causa final en el llamado Estado de derecho. 
esto es, a los órganos jurisdiccionales en el ejercicio de su función en el Estado constitucional de derecho- debe dejar de ser un mito (una ficción, una ilusión, una fantasía, algo ideal, una entelequia, una abstracción, algo inmaterial, algo abstracto).

Una vez señalados los antecedentes que originaron el enunciado de esta ponencia, nos ocuparemos de ampliar el contenido semántico de las locuciones del tema en referencia. En principio, podemos afirmar que la deontología intenta regular la conducta o las normas éticas del profesional de cualquier rama determinada de las ciencias. En el caso que nos ocupa, podemos hablar de una deontología jurídica que intenta regular la conducta del profesional del derecho sea cual fuere la actividad a la que se dedique en esta profesión. Más específicamente, se trata de referir en este estudio la trascendencia de la deontología con la actividad del togado. La ciencia del deber apunta a unos fines, tiene un propósito fundamental en la recta función estatal de los jueces. El concepto de deontología fue acuñado por Jeremías Bentham $(1834 ; 1836)^{4}$ en su obra Deontología o ciencia de la moral5. De esta forma, la deontología se conecta con el enjuiciador para un correcto ejercicio de la función jurisdiccional que le ha sido encomendada, en tanto conjunto de normas vinculantes derivadas de la ética normativa. Asimismo, debemos advertir que la ciencia del deber se corresponde con una manera de entender el mundo y la vida, esto es, con una filosofía del ser humano como un ser cultural, portador de unos valores sociales y jurídicos.

4. Para Bentham $(1834 ; 1836 a ; 1836 b)$, la base de la deontología debería sustentarse en los principios filosóficos de la libertad y el utilitarismo, asimilándola a partir de sus fines (el mayor bienestar posible para la mayoría y de la mejor forma). No vamos entrar en la crítica que se endereza al pensamiento utilitarista de Bentham, en el sentido de que es imposible objetivar, en términos científicos, o computar la felicidad para comprobar la mayor cantidad de bienestar alcanzable. No está en nuestro ánimo generar aquí una discusión filosófica. Nuestro propósito apunta a destacar a la deontología, en tanto ciencia de deber, como una herramienta para proporcionar un conjunto de normas y principios que regulen la ética judicial, considerada como prenda necesaria de los jueces en el ejercicio de la función jurisdiccional. En este sentido, Bentham concibe a la deontología como un conjunto de reglas de comportamiento en las relaciones interpersonales de la sociedad: «La Deontología le enseñará la conducta que ha de observar con respecto a los hombres en general, haciéndole ver cómo deben modificarse sus actos por todas las circunstancias, que llaman toda su atención especial en sus relaciones sociales» (Bentham, 1836b, p. 6).

5. Para este trabajo hemos consultado la obra de Bentham en dos versiones, ambas publicadas de manera póstuma, ya que murió en 1832. La versión inglesa, Deontology or, The science of morality, publicada en Londres en 1834 y cuya edición en dos tomos estuvo a cargo de John Bowring. Asimismo, la edición traducida al español deriva de la versión francesa que, a su vez, fue traducida de la versión inglesa, indicada al comienzo de esta cita. La edición en castellano, Deontología o Ciencia de la Moral, fue publicada en México en 1836 por la Librería de Galván, Portal de Agustinos y traducida por D.P.P. Ambas ediciones pueden consultarse en: https:// archive.org/details/deontologyorthes01bentuoft y http://bibliotecadigital.jcyl.es/i18n/consulta/ registro.cmd?id=17097, respectivamente. 
Siguiendo esta idea, el juzgador conecta en su formación técnicojurídica con su entorno cultural, lo que le permite una lectura de valores, de principios, que son los que debe afirmar, mediante la aplicación de normas, al emitir sus fallos. En la alta función jurisdiccional encomendada al juez en la búsqueda incesante de la justicia, en tanto causa final de su teleología y, a su vez, entendida aquella como valor supremo del derecho, no es suficiente la aplicación del método técnico-jurídico. Además, se necesita como requerimiento metódico del enfoque científico-político y, desde luego, en tanto condicionante inexorable en la aplicación del derecho para la consecución de la justicia, de la formación axiológica. Estas consideraciones conceptuales se complementan en la función del juez a la hora de decidir sobre las libertades.

En principio podemos afirmar que para los jueces su cultura, su sistema jurídico, su filosofía de vida tienen un origen grecolatino, en tanto que concurren con las sociedades occidentales o euroatlánticas, como contingentes bumanos que han participado de una matriz cultural común, que deriva de una triple impronta material-espiritual: la grecorromana, la germánica y la judeo-cristiana. En nuestra opinión, estas influencias civilizatorias -conjunto de hechos, escritos, modos de pensar e interpretar el cosmos que proponen una concepción del mundo y de la vida- confluyen, sustantivamente, para identificar la cultura occidental. En principio, todo lo anterior influye en matizar, estructurar y definir el concepto del deber del juzgador y, desde luego, en su formación axiológica y su consideración ética.

El juez está investido, seguramente, de una de las más altas responsabilidades que un profesional del derecho pueda poseer. En nuestro concepto, la deontología se presenta en el juzgador como una premisa sine qua non, es decir, como una solicitud sin la cual el que porta esta noble investidura no puede cumplir con el fin último del derecho: la justicia. El telos de la deontología judicial es el servicio de la justicia y su materialización, en tanto valor supremo del derecho. Este es el verdadero problema al que se enfrenta el sentenciador. Afirmamos, sin duda alguna, que es menester contar con una sólida formación ética, como condición inexorable para conseguir los más altos fines sociales. El juzgador realiza un acto racional de conocimiento, pero si no existe previamente una voluntad dirigida por una sólida alineación ética, ciertamente la realización de la justicia quedará en entredicho. Por eso, como sostiene el jurista Uruguayo Eduardo Juan Couture, «Que el juez sea un caballero, que sea un señor, y si sabe Derecho, mucho mejor» (citado por Vásquez \& Zapata, s.f., p. 59). Qué es ser un caballero... 
Al menos significa nobleza, lealtad, educación, cortesía. Qué entendemos por señor... Con esta voz se denota una persona educada y de nobles sentimientos, enorme, grande, con decoro y autoridad. Este último vocablo proviene del latín auctoritas, y a su vez de auctor, cuya raíz es augere, que significa ayudar a hacer crecer...

Hablar hoy en día de justicia probablemente no se trate de una circunstancia excepcional. Cuántas veces a lo largo de la historia se han experimentado vaivenes, altibajos, en la materialización de este excelso valor de todo ordenamiento jurídico, pero ni duda cabe de que, en la actualidad, no atraviesa por un buen momento. Si le preguntásemos al más humilde de los ciudadanos sobre la medición de la justicia, es decir, si vive en un auténtico Estado de derecho, y si existe una justicia real, social y diligente, seguramente nos contestará en muchos de los casos que la justicia es algo que está ausente, que no se palpa, que es intangible, que existe como una entelequia abstracta de carácter formal, pero que no llega a concretarse en muchos de sus conciudadanos y en su persona.

Así pues, incluir el vocablo desmitificación en el contenido de la presente comunicación derivó de la lectura de un texto que adquirimos en una librería de libros antiguos en Madrid. La obra contiene numerosas sentencias vinculadas a la justicia, a los tribunales y a la profesión de la abogacía, y que utilizan la voz mito. La voz empleada en el título de esta propuesta es desmitificación, y se utiliza despojándola del carácter mítico. Nos referimos a la obra Toga y justicia escrita por el jurista vallisoletano, que radicó en la Villa del Oso y el Madroño y prematuramente desaparecido (1911-1954), Reinaldo Temprano Azcona, y publicada por la casa editorial Astrea de Valladolid.

Solo a manera de muestra, citamos dos máximas contenidas en el libro y que utilizan la palabra mito: «El mito de la justicia social sigue en el aire y sin ánimos de tocar tierra» (p. 8). «La igualdad ante la ley sigue siendo uno de los mitos, más mitos, de la mitología humana» (p. 27). A mayor abundamiento sobre esta entrada, hemos referido que el libro fue publicado por la editorial Astrea. Y Astrea era hija de Temis y Zeus, dioses de la mitología griega; junto con su madre, ella era considerada diosa de la justicia. Por consiguiente, al referirnos a la desmitificación, anunciamos que la justicia debe ser desdivinizada, esto es, secularizada; pretendemos indicar que, mediante este recurso lingüístico, los problemas que los justiciables lleven a los tribunales dejen de considerarse, en muchos casos, como una serie de procesos que solo pueden explicarse en términos narrativos, mitológicos, etéreos o fabulosos, es decir, inexistentes. Se trata, en definitiva, de que los 
conflictos y las diferencias de los gobernados puedan considerarse como un conjunto de actos racionales y concretos, para tratarlos y resolverlos mediante un conjunto de diligencias normativo-institucionales.

Se requiere, a fortiori, como requisito insoslayable, la formación ética del árbitro judicial para la consecución de la justicia, lo que posibilitaría un avance muy importante en su desmitificación, es decir, una transición del mito al logos. Sin justicia no puede haber paz, y sin esta, progreso, que es ley de vida. De ahí nace la delicada función de los jueces de impartir una pronta, expedita y correcta justicia. El juez tutela los valores más preciados del hombre para una adecuada y pacífica convivencia social en el Estado. La libertad es, quizás, el valor más importante del ciudadano en un Estado de derecho. De esta forma, los derechos humanos representan concreciones jurídicas de las libertades públicas individuales y sociales. El juez se convierte en pieza clave dentro del Estado de derecho, ya que decide sobre el significado y el alcance de dichas libertades; por ello debe procurar generar, con esta actividad técnico-jurídica, una armonía social. La administración de justicia es pieza clave en todo sistema jurídico-político. La función meridional del Estado de derecho pasa por el poder judicial, por la actividad jurisdiccional. Su teleología no puede ser más augusta ni de mayor envergadura ni repercusión social. A tan delicada tarea está confiada la protección del honor, la vida y los bienes de los ciudadanos.

Nadie puede poner en duda que la actuación del juez en toda comunidad política es capital. Tiene un gran reto ante las grandes adversidades en la crisis moral y social que vivimos. La vida -afirmaba Pío Baroja (1973), y su pensamiento sigue teniendo vigencia- es esto: crueldad, ingratitud, inconsciencia, desdén de la fuerza para con la debilidad. Es una constante en la humanidad, el dominio y la explotación de los hombres hacia otros. Creemos firmemente que los malos actúan en función de los buenos, queremos decir que, si no hubiera buenos, los malos no tendrían razón de ser ni de existir, porque no tendrían tareas que cumplir. Los buenos deben ser más que los malos y enfrentarlos para revertir la situación. Aceptar que el mundo es solo de los malos sería contribuir -otra vez- al engaño y la injusticia. Es necesario admitir la existencia del Estado, en tanto entidad soberana e institución suprema de derecho. Es decir, el Estado apunta a unos fines ético-sociales de orden y seguridad, para la consecución de la vida colectiva, pacífica y sosegada. En definitiva, el Estado tiene una justificación no solo jurídica y política, sino axiológica. Por ello, no le faltaba razón a Thomas Hobbes (1882) cuando afirmó en su Leviatán que: «[...] Es manifiesto que, durante el tiempo en que los hombres 
viven sin un poder común que los atemorice a todos, se hallan en la condición o estado que se denomina guerra, una guerra tal que es la de todos contra todos» (p. 107). Esta reacción de Hobbes fue motivada por los graves conflictos sangrientos y la situación de perpetua guerra en la que vivían los individuos de su tiempo; y lo ubicó como un apologista del Estado moderno a pesar de ser absolutista, esto es, había que aceptar una institución de poder absoluto a la cual todos los Estados deben su paz y su defensa, tratando de evitar con ello una «Bellium Omnim Contra Omne».

En 1521, el teólogo protestante alemán Philipp Melanchthon ${ }^{6}$ expresó en su obra Lugares comunes de la teología una frase muy significativa «Hágase justicia aunque perezca el mundo ${ }^{7}$ » (citado por Colegio de Abogados Procesalistas Latinoamericanos, 2016-2017). Más tarde el filósofo de Königsberg, Emanuel Kant (2003), la recogería en su obra La paz perpetua, en los siguientes términos: «Hay una frase que, a pesar de cierto dejo de fanfarronería, se ha hecho proverbial y es muy verdadera. Fiat justitia, pereat mundus. Puede traducirse así: Reine la justicia, aunque se hundan todos los bribones que hay en el mundo» (p. 22) ${ }^{8}$. Aquel aforismo, a su vez, fue popularizado por Fernando I de Habsburgo. Posteriormente, el discípulo más conspicuo de Kant, Frederick Hegel, matizó la máxima que divulgó su maestro para quedar como sigue: «Hágase justicia para que no perezca el mundo» (Valadés, 2002, p. 219). En definitiva, se trata de evitar, en un auténtico Estado de derecho, que el hombre se haga justicia por su propia mano, esto es, evitar la vindicta privada propia de la época medieval y de otras épocas.

El papel que desempeñan los jueces es muy importante y delicado, ya que saltan a la vista cuestiones que les son propias, como las siguientes: sobre el carácter político o no de su actividad; sobre si se limitan a aplicar leyes o son creadores de derecho; si la justicia es un poder ubicado a la misma altura del legislativo y el ejecutivo; si la actividad judicial de interpretación y de aplicación del derecho es un acto racional de conocimiento, o un acto de voluntad, o ambas cosas; o cuál debe ser el Estatuto jurídico más adecuado para garantizar su independencia y la objetividad de sus resoluciones, etc.

Nunca hay que olvidar los equilibrios. El juez es el protector de los bienes jurídicos mayormente apreciados por el derecho: la vida y las libertades, entre otros. El gran teórico de la moderación, Charles

6. Padre de la educación de su patria en esa época, compañero de viaje y continuador de la filosofía de Martín Lutero.

7. «Fiat justitia, et pereatmundus».

8. También recogido por Álvarez Gómez \& Paredes Martín (2002), p. 171. 
de Secondat Barón de la Brede y Montesquieu (1906) nos comentaba que:

La democracia y la aristocracia no son Estados libres por su naturaleza. La libertad política sólo se halla en los gobiernos moderados; mas no siempre está en ellos, sino únicamente cuando no se abusa de la autoridad; pero se sabe por experiencia eterna que todo hombre investido de autoridad propende a abusar de ella, no deteniéndose hasta que encuentra límites. ¡Quién lo diría! La misma virtud tiene necesidad de límites (p. 15).

Antes de cerrar nuestra intervención y siguiendo un extraordinario artículo que escribió el ya finado don Gregorio Peces Barba en la tradicional «Editorial Tercera» del periódico $A B C$ de España, queremos participarles algunas reflexiones que el maestro español desarrolló sobre la función judicial, las cuales hemos sintetizado y parafraseado. Esta serie de cualidades que debe poseer todo juzgador pueden llevarse a cabo cuando se tiene una solvencia moral, una sólida densidad ética, ya que se refieren a una serie de conductas que deben observar los togados, como garantes del Estado de derecho en toda comunidad política, para alcanzar la tranquilidad y el progreso social.

$\mathrm{El}$ poder judicial debe tener un papel en esta función esencial del Estado, ya que en la actualidad, con la facilidad de las comunicaciones, el juez aparece de una manera más visible en la sociedad, menos distante y a su vez más protagonista en la problemática que vive la comunidad, y esta, asimismo, ante la igualdad formal, aumenta sus pretensiones ante los tribunales.

El juez debe pasar por las siguientes coordenadas que le permitan desempeñar su función en esta delicada y primerísima actividad estatal:

- Debe contar, antes que nada, con una sólida formación ética.

- Su legitimación le viene de la Constitución y de la ley, es decir, su actuación debe ser con estricto apego al derecho. Solo el ordenamiento jurídico, el cual aplica e interpreta, le habilita y otorga autoridad.

- Debe tener una formación jurídica, histórica, filosófica, sociológica y artística, ya que son necesarias para que pueda discernir y aportar los hechos y los fundamentos jurídicos que se le presenten a su consideración. En definitiva, una vasta cultura universal. Un puro técnico, que conoce solamente los términos

9. Exrector de la Universidad Carlos III de Madrid, España. 
jurídicos, pero nada más, no es un buen juez. No queremos decir que no sea importante la formación jurídica y, específicamente, que cuente con el perfil especializado del juzgador. Las humanidades, la literatura y el conocimiento de los clásicos, desde la Antigüedad hasta nuestros días, no son un adorno, sino una exigencia para desempeñar mejor su trabajo.

- En su actuación debe ser lo más objetivo posible y hacer valer su independencia derivada de la ley. Al juzgar, escoge los hechos relevantes, las normas aplicables al caso concreto y, por ello, está haciendo política (no en el sentido electoral o partidario), pues al tomar decisiones, estas afectan al interés general y a la libertad. El juez juzga sobre problemas relevantes para la vida, el honor o la dignidad para las personas y, en esa medida, está haciendo una actividad política de manera aún más visible. Recordemos que el adjetivo de la propia Constitución la califica de «política».

- Cuando emite sus fallos, debe conceder respuestas correctas y soluciones juiciosas a los problemas que ocurren en su jurisdicción y que no son solo producto de argumentaciones (insustituibles para la dignidad de su tarea), sino también manifestaciones de su voluntad. La justicia es, quizás antes que nada, un acto de voluntad. Así, la experiencia de la vida, el conocimiento cabal de la realidad de la sociedad y de los hombres son el complemento práctico inseparable del teórico.

- En el desempeño de su función, debe ser discreto, ya que las permanentes informaciones y opiniones, desde los distintos medios de comunicación respecto de los juicios o procesos sometidos a su jurisdicción, pueden tener dos consecuencias negativas: afectar a la independencia de la magistratura y motivar un inconveniente protagonismo público que afecte su discreción, imparcialidad y objetividad. Por consiguiente, cuando la moralidad desde la que se juzga un caso concreto coincide con los intereses propios, indica que se carece de moralidad. Después vendrá la crítica a las resoluciones judiciales, y que es una base indispensable del funcionamiento de las sociedades democráticas, pero debe hacerse con un equilibrio y con mesura basados siempre en argumentos racionales.

- En su vida cotidiana debe manifestarse con discreción y abstenerse de intervenir activamente en la vida pública, criticando al Gobierno o a la oposición, haciendo ruedas de prensa en cada momento, queriendo llamar la atención, manifestándose 
en entrevistas radiofónicas o aceptando homenajes públicos, lo cual le introduce en la controversia y en la polémica en detrimento de la respetabilidad de sus resoluciones. El enjuiciador, para ser eficaz y respetado por todos, solo debe hablar con contundencia y autoridad en sus resoluciones, autos y sentencias, y es para lo que ha sido habilitado. La independencia, claro está, no solo se pierde por presiones ajenas, sino también con actitudes propias.

- Este modelo de juez, con una formación ética, humanística y jurídica seria; objetivo e independiente, abierto a los problemas que tiene que resolver, discreto y ajeno a los avatares de la pequeña política diaria y a una presencia pública, fuera de los casos difíciles que solo él debe decidir, está en condiciones óptimas de crear derecho en una sociedad donde, junto al compositor, el legislador, está el juez intérprete.

Por todo lo anterior, los jueces están muy presentes en la realidad política y jurídica de nuestros días, y es necesario que tengan una formación jurídica sólida y una densa cultura general. Ya con justa razón Oliver Wendell Holmes, el gran juez norteamericano, ministro de la Suprema Corte por treinta años, y que llegó a ser considerado por alguno como «La figura más ilustre en la historia del derecho norteamericano», describía al tipo de magistrado ideal como «Ariel y Prometeo y Júpiter, con algunos aspectos de Mefistófeles también» (citado por Schwartzen, 1979, p. 425).

Por último, no nos quedaríamos tranquilos ni satisfechos si no hiciéramos dos breves reflexiones. En cuanto a la primera, y perdonen que seamos tan insistentes con este tema, la veracidad y la sapiencia son prendas que el juzgador debe tener para realizar adecuadamente la altísima y delicada función de impartir justicia. El magistrado está investido de la más noble y trascendental función del Estado. Para ser buenos juzgadores se requiere, como mínimo, la exigencia de conocimientos, de sabiduría, de valor pero, sobre todo, de calidad moral; y para lograr tal cometido hay que tener presente que no debe primar la necesidad de acumular riquezas, de adquirir aparente crédito y falsos honores, puesto que no se deben despreciar los tesoros de la verdad y la sabiduría, todas ellas premisas inexorables para su recta función. Esto coincide con tres preceptos esenciales que fundamentan la teoría del derecho romano, producto de su sabiduría jurídica: honeste vivere, alterum non laedere, suum cuique tribuere (vivir honestamente, no dañar al otro y dar a cada quien lo suyo). Un juez que tenga presente 
lo anterior podrá tener tranquilidad de consciencia al desempeñar su función en la aquendidad y estar seguro de que su alma, cuando llegue el momento, será considerada con justicia.

En la segunda meditación, citaremos dos veces a Sócrates. El también inmortal Aristóteles lo consideró, por la conducta mostrada, padre fundador de la ética. Sócrates refirió cuatro características que le corresponden al juez: «Escuchar cortésmente, responder sabiamente, ponderar prudentemente y decidir imparcialmente» (citado por Zermeño Infante, 2006, p. 107). Todas estas cualidades solamente puede poseerlas el juzgador cuando tiene una ineluctable formación ética. En la segunda cita, Sócrates concluyó, en la parte final del juicio que lo condenó a muerte, dirigiéndose a todos los que permanecieron vivos después de beber la cicuta, lo siguiente:

Cuando mis hijos sean mayores, les suplico que los hostiguen, los atormenten, como yo los he atormentado a ustedes, si ven que prefieren las riquezas a la virtud, y que se crean algo cuando no son nada; no dejen de exponerlos a la vergüenza, si no se aplican a lo que deben aplicarse, y creer ser lo que no son... Si me conceden esta gracia, mis hijos y yo no podremos menos que alabar su justicia (Azcárate (ed.), 1871, p. 86).

\section{Referencias}

Álvarez Gómez, M. \& Paredes Martín, M. (2002). La Controversia de Hegel con Kant. Salamanca: Ediciones Universidad de Salamanca. Baroja, P. (1973). El mundo es ansí. Madrid: Editorial Espasa Libros. Bentham, J. (1834). Deontology or, The science of morality. Londres: Longman, Rees, Orme, Green, and Longman. Recuperado de: https://archive.org/details/deontologyorthes01bentuoft.

Bentham, J. (1836a). Deontología o ciencia de la moral. I t. Méjico: Librería de Galván, Portal de Agustinos. Recuperado de https:// bibliotecadigital.jcyl.es/es/consulta/registro.cmd?id=17097.

Bentham, J. (1836b). Deontología o ciencia de la moral. II t. Méjico: Librería de Galván, Portal de Agustinos. Recuperado de https:// bibliotecadigital.jcyl.es/es/consulta/registro.cmd?id=17097.

Colegio de Abogados Procesalistas Latinoamericanos (2016-2017). Aforismos jurídicos. Primera Instancia. Revista Jurídica. Recuperado en: http://www.primerainstancia.com.mx/derechos-economicossociales-y-culturales/httpswww-youtube-comwatchvafzfq7i4wvslistuu0aic5he5jubfmeftyuuydw/aforismos-juridicos/. 
Couture, E. Juan. Citado por Vázquez, M. \& Zapata, V. (s/f). En: La ética en el Poder Judicial de la Federación. Instituto de Investigaciones Jurídicas de la UNAM. Biblioteca Jurídica Virtual. Recuperado en: http://historico.juridicas.unam.mx/publica/librev/rev/qdiuris/cont/9/cnt/cnt4.pdf. p. 59.

Gómez Sámano J. S. (2012). Juez creador de historia. El juez como espectador, actor y director de la historia en la modernidad. En Revista del Instituto de la Judicatura Federal, (34), pp. 69-97.

Hobbes, T. (1982). La materia, forma y poder, de una República Eclesiástica y Civil. Leviatán. Bogotá: Editorial EDSKLA.

Kant, E. (2003). La Paz Perpetua. Editorial del Cardo, Biblioteca Virtual Miguel de Cervantes. Recuperado de http://www.biblioteca. org.ar/libros/89929.pdf.

Montesquieu, C. (1906). El espíritu de las Leyes. I t. Madrid: Librería General de Victoriano Suárez. Recuperado de http://fama2.us.es/ fde/ocr/2006/espirituDeLasLeyesT1.pdf.

Peces Barba, G. (24 de marzo de 1993). Sobre los jueces. ABC.

Platón (1871). La Apología de Sócrates. En P. Azcárate (Ed.), Platón, Obras completas (pp. 49-86), I t. Madrid: Medina y Navarro Editores.

Real Academia Española (2014). Diccionario de la Real Academia Española. 23. a ed. Recuperado de http://dle.rae.es/?w=diccionario.

Schwartzen, B. (1979) The Judicial ten American Greatest judges. Illinois University Law Journal (3), pp. 405-447.

Temprano Azcona, R. (1954). Toga y justicia: mis pensamientos. Valladolid: Astrea.

Valadés, D. (2002,enero abril). La no aplicación de las normas y el Estado de derecho. Boletín Mexicano de Derecho Comparado, XXXV(103), pp. 219-291.

Vázquez, M. \& Zapata, V. (s.f.). La ética en el Poder Judicial de la Federación. Instituto de Investigaciones Jurídicas de la UNAM. Biblioteca Jurídica Virtual. Recuperado de http://historico.juridicas. unam.mx/publica/librev/rev/qdiuris/cont/9/cnt/cnt4.pdf.

Zermeño Infante, A. (2006) «Cuatro características corresponden al juez: escuchar cortésmente, responder sabiamente, ponderar prudentemente y decidir imparcialmente», Sócrates. Revista de Derecho Notarial Méxicano, (10), pp. 107-109. Recuperado de https:// revistas-colaboracion.juridicas.unam.mx/index.php/derecho-notarial/article/viewFile/6954/6246. 